\title{
Bullying, depressão e representações sociais no contexto escolar
}

\author{
Bullying, depression and social representations in the school context \\ Bullying, depresión y representaciones sociales en el contexto escolar
}

Fabrycianne Gonçalves Costa ORCID: https://orcid.org/0000-0003-2903-7555 Centro Universitário UNIESP, Brasil E-mail: prof1588@iesp.edu.br

Maria da Penha de Lima Coutinho ORCID: https://orcid.org/0000-0003-3961-2402 Centro Universitário UNIESP, Brasil E-mail: mplcoutinho@gmail.com Jaqueline Gomes Cavalcanti ORCID: https://orcid.org/0000-0002-3068-404X Centro Universitário UNIESP, Brasil E-mail: gomes.jaqueline@gmail.com

Márcio de Lima Coutinho

ORCID: https://orcid.org/0000-0003-1092-7566 Centro Universitário UNIESP, Brasil prof1589@iesp.edu.br

Aline Arruda Rodrigues da Fonseca ORCID: https://orcid.org/0000-0002-5805-2650 Centro Universitário UNIESP, Brasil E-mail: prof1813@iesp.edu.br

\begin{abstract}
Resumo
O Bullying é um fenômeno caracterizado pelo conjunto de atos de violência física ou verbal, que ocorrem contra um ou mais vítimas, tais comportamentos de forma repetitiva e intencional podem desencadear sintomas depressivos nos envolvidos. Dessa forma, objetivou-se apreender as representações sociais elaboradas por adolescentes acerca do bullying e da depressão. Participaram da pesquisa 31 adolescentes com idades entre 12 e 18 anos, de uma escola pública. Foram utilizados um questionário sociodemográfico e uma entrevista semiestruturada. A aplicação dos instrumentos ocorreu individualmente, os dados do questionário foram analisados utilizando a estatística descritiva e inferencial. Quanto às entrevistas, utilizou-se a Análise de Similitude, Nuvem de palavras e Classificação Hierárquica Descendente. Os participantes demonstraram conhecimento multifacetado acerca do bullying e da depressão, ancorando-os nas vertentes conceitual, comportamental, implicações psicoemocionais, tipos de bullying e bullying enquanto sinônimo de brincadeira. Destaca-se que os comportamentos de bullying evidenciados no estudo foram referentes à agressão física, verbal e psicológica, o que pode levar à negligência da higiene pessoal, tristeza, desânimo, baixo rendimento escolar, problemas familiares e a falta de apoio. Por outro lado, os adolescentes também apontaram o bullying enquanto sinônimo de brincadeira, delineando esse fenômeno como algo naturalizado. Evidencia-se a necessidade de intervenções mais efetivas nesse contexto, contemplando estratégias sobre a conscientização das consequências do bullying e minimização do sofrimento emocional desencadeado.
\end{abstract}

Palavras-chave: Bullying; Depressão; Representação social.

\begin{abstract}
Bullying is a phenomenon characterized by the set of acts of physical or verbal violence that occur against one or more victims, such behaviors repetitively and intentionally can trigger depressive symptoms in those involved. Thus, the objective was to apprehend the social representations elaborated by adolescents about bullying and depression. Thirtyone adolescents aged between 12 and 18 years old, from a public school participated in the research. A sociodemographic questionnaire and a semi-structured interview were used. The instruments were applied individually, the questionnaire data were analyzed using descriptive and inferential statistics. As for the interviews, the Similitude Analysis, Word Cloud and Descending Hierarchical Classification were used. Participants demonstrated multifaceted knowledge about bullying and depression, anchoring them in the conceptual, behavioral, psycho-emotional implications, types of bullying and bullying as a synonym for play. It is noteworthy that the bullying behaviors evidenced in the study were related to physical, verbal and psychological aggression, which can lead to negligence of personal hygiene, sadness, discouragement, low academic performance, family problems and lack of support. On the other hand, adolescents also pointed out bullying as a synonym for play, outlining this phenomenon as something natural. The need for more effective
\end{abstract}


interventions in this context is evidenced, contemplating strategies on the awareness of the consequences of bullying and minimization of the triggered emotional suffering.

Keywords: Bullying; Depression; Social representation.

\begin{abstract}
Resumen
El bullying es un fenómeno caracterizado por el conjunto de actos de violencia física o verbal que se producen contra una o más víctimas, tales comportamientos de manera repetitiva e intencionada pueden desencadenar síntomas depresivos en los involucrados. Así, el objetivo fue aprehender las representaciones sociales elaboradas por los adolescentes sobre el bullying y la depresión. En la investigación participaron 31 adolescentes de entre 12 y 18 años, de una escuela pública. Se utilizó un cuestionario sociodemográfico y una entrevista semiestructurada. Los instrumentos se aplicaron de forma individual, los datos del cuestionario se analizaron mediante estadística descriptiva e inferencial. En cuanto a las entrevistas, se utilizó el Análisis de Similitud, Nube de Palabras y Clasificación Jerárquica Descendente. Los participantes demostraron conocimientos multifacéticos sobre el acoso y la depresión, anclándolos en las implicaciones conceptuales, conductuales, psicoemocionales, tipos de acoso y acoso como sinónimo de juego. Es de destacar que las conductas de bullying evidenciadas en el estudio estuvieron relacionadas con agresiones físicas, verbales y psicológicas, las cuales pueden derivar en negligencia en la higiene personal, tristeza, desánimo, bajo rendimiento académico, problemas familiares y falta de apoyo. Por otro lado, los adolescentes también señalaron el bullying como sinónimo de juego, perfilando este fenómeno como algo natural. Se evidencia la necesidad de intervenciones más efectivas en este contexto, contemplando estrategias sobre la conciencia de las consecuencias del bullying y minimización del sufrimiento emocional desencadenado.
\end{abstract}

Palabras clave: Bullying; Depresión; Representaciones sociales.

\title{
1. Introdução
}

É inquestionável o poder que a violência carrega na vida de tantos que, sob a mira do medo, pavor e insegurança, apresentam na realidade em que vivem, não apenas os estigmas traçados por uma vulnerabilidade social evidente, como também panoramas influenciados pela cultura e pela forma como a sociedade trabalha as suas relações sociais. Dentro dessa perspectiva, a violência escolar, conhecida como bullying, ganha destaque, configurando-se como fenômeno social de escala mundial capaz de atingir diariamente inúmeros indivíduos (Fante, 2005).

Conforme Olweus (2013), o bullying abarca comportamentos violentos e repetitivos, que são realizados de forma sistemática e intencional. Desse modo, os envolvidos estabelecem relações desiguais de poder, nessa conjectura crianças e adolescentes assumem diferente papéis como: agressores, ao usarem da força ou do terror para agredir e machucar os colegas; vítimas, ao serem os objetos do bullying; vítimas agressoras, vítimas que também provocam; e observadores, aqueles que testemunham as cenas de violência como expectadores (Bandeira \& Hutz, 2012). Tais comportamentos têm o objetivo de maltratar e gerar dor, angústia e sofrimento, no outro e podem ser de forma física, verbal, relacional ou social e eletrônica, denominado como cyberbullying (Terroso et al., 2016).

Historicamente, o termo bullying foi utilizado primeiramente na Inglaterra, ao fazer alusão às agressões realizadas nas organizações policiais, militares e também nas instituições escolares (Heloani \& Pinto, 2017). No que tange aos primeiros estudos acerca do bullying estes iniciaram-se na década de 1970 na Suécia e Dinamarca, mais precisamente em 1978 com a publicação do primeiro livro do professor Norueguês Dan Olweus, intitulado “Agression in the schools: bullies and whipping boys”. Desde então, várias outras pesquisas foram desenvolvidas visando a conscientização acerca do respeito ao problema atrelado a esse tipo de violência escolar e a remoção da "cultura do silêncio", envolta por esse tipo de dinâmica capaz de destruir o tecido social. No Brasil, os estudos sobre a temática iniciaram- se por influência da obra de Fante (2005), intitulada: "Fenômeno Bullying: como prevenir a violência nas escolas e educar para paz", quando a temática passou a ser alvo de discussões e pesquisas científicas. Apesar dos estudos sobre o bullying escolar no Brasil serem recentes, o fenômeno é antigo e preocupante, tendo em vista seus efeitos nocivos (Fante, 2005; Lospes, 2005; Oliveira-Menegotto et al., 2013; Heloani \& Pinto, 2017).

Com base na literatura, observa-se que esse fenômeno epidêmico é capaz de proporcionar um ciclo de abuso e vulnerabilidade, e apresenta em sua conjuntura uma tipologia que abarca o bullying direto, no qual as vítimas são atacadas 
abertamente; o bullying indireto, realizado de forma mais implícita e sutil, seja através de isolamento social, da exclusão intencional do grupo e, por último, do cyberbullying que proporciona o anonimato e não exige, necessariamente, uma relação desigual de poder (Olweus, 2013; Terroso et al., 2016).

Em meio a todo esse arcabouço, o bullying ainda traz consigo, implicações e consequências biopsicossociais que podem ser observadas de diversas formas. Para Garcia (2013), as consequências para as vítimas desse fenômeno são graves e abrangentes, podendo promover no âmbito escolar, o desinteresse desses indivíduos pela escola o déficit de concentração e aprendizagem, a queda de rendimento, o absentismo e a evasão escolar. $\mathrm{Na}$ área da saúde física e mental, observa-se que ocorre uma baixa na resistência imunológica e autoestima, assim como a presença do estresse, de sintomas psicossomáticos e transtornos psicológicos, como é o caso da depressão. Em casos mais extremos, se não tratado, pode ocasionar o suicídio.

A depressão, segundo a Organização Mundial de Saúde (OMS), encontra-se no hall das doenças mais comuns atualmente, abrangendo uma prevalência de 300 milhões de casos no mundo, visto ser um fenômeno que a cada dia a cada dia ganha força, território e poder em meio à vida de tantos, prejudicando não apenas a saúde mental, como também a qualidade de vida do indivíduo e os custos sociais que ela requer (OMS, 2021). Definida como um transtorno mental que se caracteriza pela falta de interesse pelas atividades comuns do dia a dia e por uma tristeza incessante, ela pode ocorrer em qualquer fase da vida, principalmente na adolescência, período de constantes descobertas e mudanças. Entre os fatores de risco que podem desencadear um quadro depressivo, o fator ambiental relacionado à exposição contínua à violência, negligência, abuso ou pobreza, podem tornar algumas pessoas mais vulneráveis ao aparecimento da depressão.

Diante disso, podemos associar a depressão e bullying, uma vez que a prática dessa violência, em sua maioria, desencadeia os sintomas citados do quadro depressivo em um sujeito alvo, muito embora, cada um apresente seu sofrimento de uma determinada maneira, obedecendo, assim, a subjetividade existente em cada indivíduo (Vieira et al., 2020). Em meio a esse cenário no qual bullying e depressão no contexto escolar caminham lado a lado, estudar e entender esses fenômenos, assim como o ciclo de violência e de vulnerabilidade social que eles abarcam, é de extrema relevância para uma sociedade que cada vez mais está atenta e disposta a romper de vez com a cultura do silêncio em meio a tantas tragédias, posturas e comportamentos existentes dentro de uma dinâmica de violência capaz de amedrontar e transformar, de forma significativa, a vida de todos ao seu redor.

Nesse âmbito, o bullying e a depressão correspondem a fenômenos plurifacetados que traz, na Teoria das Representações Sociais (TRS), um aporte para melhor compreender a realidade que perpassa as relações do ser humano com o meio físico e social que o compõe. Conforme essa teoria é possível interpretar a realidade, comportamentos, atitudes e práticas que guiam o indivíduo nas ações sociais as quais norteiam o seu dia a dia, levando em conta o aporte teórico, experiências, comunicações, cultura e fatos do cotidiano, configurando-se assim, como algo mutável e em constante desenvolvimento (Cavalcanti et al., 2019).

Para Moscovici (2012), as representações sociais se referem a um fenômeno típico da sociedade moderna. Ao se construir a representação de um determinado objeto, o sujeito de certa forma o constrói, o reconstrói em seu sistema cognitivo, de modo a adequá-lo ao seu sistema de valores. Dessa forma, quando o indivíduo classifica um fenômeno que acontece ao seu redor, significa dizer que ele parte de seu conjunto de referências construídas internamente.

As representações sociais (RS) de um grupo resultam de um processo de transformação do que não é familiar e não conhecido em algo familiar e particular, envolvendo assim, dois processos básicos: a ancoragem e a objetivação (Moscovici, 2012). A ancoragem seria o processo em que o sujeito dá significado ao objeto, relacionando as práticas e valores que o grupo tem em comum. A objetivação é o processo pelo qual o indivíduo transforma a ideia de um conceito para algo concreto. Deste modo, os comportamentos relacionados ao bullying e os significados que ele traz para determinado grupo parte da forma como o sujeito ancora suas ideias (Moscovici, 2012). 
Apesar do tema bullying já estar muito popularizado no âmbito escolar, as pesquisas utilizando o enfoque teórico das representações sociais e associando-o à depressão no período da adolescência são incipientes. Conforme constatado após a busca de produções científicas em artigos brasileiros relacionados ao bullying e depressão sob a perspectiva psicossocial, utilizandose os descritores "bullying" AND "depressão" AND "representações sociais", no portal da Capes, sem delimitar as bases de dados, encontrou-se seis artigos, no entanto nenhum deles fazia menção à temática proposta. Ao considerar os temas bullying e representação social visualizou-se duas pesquisas realizadas com adolescentes no contexto escolar (Araújo et al., 2012; Cavalcanti et al., 2019). No que tange ao tema depressão e RS foram encontradas três produções os autores Monteiro et al. (2007) apreenderam as RS da depressão em adolescentes do ensino médio, assim como Aragão et al. (2009) e, por fim, constatou-se em Ribeiro et al. (2010), que realizaram o estudo em uma instituição da rede pública de ensino. De modo geral, não foram constatados estudos associando bullying, depressão e representação social com adolescentes. Contudo, em pesquisa integrativa da literatura no portal de revistas Scielo, sobre depressão e bullying no contexto escolar, foram encontrados 15 artigos. Os critérios de inclusão foram: dialogar sobre depressão e bullying e ter amostra constituída por adolescentes. Não houve filtro para país ou ano de publicação, assim, após esses critérios permaneceram nove artigos.

Desses estudos, os que foram realizados por Valle et al. (2015), Cosma et al. (2015) e Forlim et al. (2014) apontam para uma relação direta entre ser vítima de bullying, sentir estados emocionais negativos e sintomas de depressão, além de ter sido encontrado também ideação suicida (Ato et al.,2018, Azúa et al., 2020). Mostrando que alunos alvo de bullying têm mais chances de ter sintomas de depressão do que outros estudantes que não são alvo.

Sobre verificar se existiu algum tipo de intervenção por parte da escola, Montejo et al. (2019), Palomares-Ruiz et al. (2019) e Schoombie e Zyl (2011) colocaram esse ponto em seus objetivos de pesquisa e verificaram que estava sendo traçado o perfil da vítima e o ambiente que esta encontrava-se inserida, mas não um trabalho de intervenção diretamente com os escolares. E também houve o interesse de traçar o perfil das vítimas de bullying e agressores (Montejo et al., 2019; Palomares-Ruiz et al., 2019; Resett, 2018).

Sendo assim, objetivando apreender as representações sociais elaboradas por adolescentes acerca do bullying e da depressão, o presente artigo configura-se como um importante instrumento a ser utilizado por estudantes e profissionais que procuram compreender como as representações sociais acerca desses fenômenos podem influenciar a vida dos adolescentes, fenômenos que, assim como a vida, são complexos e mutáveis, visto o fato de o ser humano se encontrar em constante evolução.

\section{Metodologia}

Trata-se de um estudo de campo, do tipo exploratório, de coorte transversal, de abordagem multimétodos, fundamentado na teoria das representações sociais. A pesquisa foi desenvolvida em uma escola da rede pública de ensino, localizada na cidade de João Pessoa - Paraíba.

Participaram deste estudo 31 adolescentes, que compuseram uma amostra do tipo não-probabilística, de conveniência com idades entre 12 a 18 anos $(M=14,91 ; D P=1,89)$, sendo a maioria do sexo feminino (80,6\%), e do ensino médio $(61,2 \%)$. Quando questionados se já haviam se envolvido em episódios de bullying, 96,7\% afirmaram que sim; quanto ao tipo de envolvimento, a maior parte dos adolescentes relatou terem sido vítimas (38,7\%), e vítimas e agressores $(35,4 \%)$, os demais, com menor porcentagem, foram distribuídos entre observadores (9,6\%), vítimas e observadores $(6,4 \%)$, vítimas, observadores e agressores $(6,4 \%)$ e em menor número $3,2 \%$ se definiram enquanto agressores.

No que tange aos instrumentos, utilizou-se um questionário sociodemográfico e uma entrevista semiestruturada. O primeiro instrumento objetivou delinear as características dos participantes. Os adolescentes responderam a um questionário sociodemográfico, composto por questões como: sexo, idade, escolaridade, se já haviam se envolvido em situações de bullying 
e qual teria sido o tipo de envolvimento. Ademais, a entrevista semiestruturada foi realizada para apreender as representações sociais e foi delineada a partir dos seguintes questionamentos: O que você conhece acerca do bullying? Quais os tipos de bullying você conhece? Já vivenciou alguma situação de bullying? Qual foi sua atitude? O que você conhece acerca da depressão?

Destaca-se que a pesquisa foi aprovada pelo Comitê de Ética em Pesquisa do Instituto de Educação da Paraíba - IESP, sob parecer 2.497.157 e CAAE no 81829817.6.0000.5184. Durante a sua realização, foram respeitadas todas as condições éticas estabelecidas pela Comissão do Conselho Nacional de Saúde, criada pela Resolução 466/2012 e com constituição designada pela Resolução 246/97.

Para o procedimento de coleta dos dados, realizou-se contato prévio com a direção da instituição escolar com o intento de conferir a autorização dos responsáveis pelos alunos para o procedimento de coleta de dados. A seguir, e com a disponibilidade dos estudantes para a participação voluntária nesta pesquisa, foram explicitados os objetivos pertinentes ao estudo, além de garantido o anonimato e confidencialidade das respostas proferidas pelos participantes, uma vez que os dados foram tratados em seu conjunto.

Quanto à aplicação dos instrumentos, esta se deu de forma individual, nas próprias dependências da escola pesquisada, sob a responsabilidade das pesquisadoras devidamente treinadas, durante os meses de agosto a novembro de 2018. O número de participantes foi estabelecido segundo o critério de saturação definido por Sá (1998). De acordo com este critério, as entrevistas podem ser encerradas no momento em que os conteúdos temáticos começarem a se repetir e não surgirem elementos novos ou diferenciados nas falas dos participantes.

No que tange à análise dos dados, o material proveniente do questionário sociodemográfico foi analisado por meio do Pacote Estatístico para as Ciências Sociais (SPSS - 21.0), utilizando-se da estatística descritiva (média, desvio padrão e frequências). Os dados coletados a partir das 31 entrevistas, as quais foram gravadas e transcritas na íntegra, originou um corpus que foi processado pelo software IRAMUTEQ (Interface de R pourles Analyses Multidimensionnelles de Texteset de Questionnaires). Este programa informático viabiliza diferentes tipos de análise de dados textuais, desde a lexicografia básica (cálculo de frequência de palavras), até as análises multivariadas (Classificação Hierárquica Descendente [CHD] e análises de similitude), dessa forma, o software estabelece a distribuição do vocabulário de modo naturalmente compreensível e visualmente claro (Camargo \& Justo, 2013).

$\mathrm{Na}$ CHD, os segmentos de texto são classificados em detrimento de seus correspondentes vocabulários, e a junção destes é dividida em função da frequência das formas reduzidas. Esse tipo de análise tem como objetivo obter classes de segmentos de texto que concomitantemente apresentam vocabulários semelhantes entre si, e vocabulários diferentes dos segmentos das outras classes, assim, com base nesse exame, o programa estabelece a análise dos dados em um dendograma que apresenta as relações de proximidade e distanciamento entre as classes (Camargo \& Justo, 2013). A análise de similitude se fundamenta na teoria dos grafos e possibilita identificar as concorrências entre as palavras e seu resultado, fornecendo indicações da conexão entre as palavras, contribuindo na identificação da estrutura de um corpus textual. Distingue ainda as partes comuns e as especificidades em função das variáveis descritivas identificadas na análise. Já a nuvem de palavras as agrupa e as organiza graficamente em função da sua frequência (Camargo \& Justo, 2013).

\section{Resultados e Discussão}

O presente estudo objetivou apreender as representações sociais elaboradas por adolescentes acerca do bullying e da depressão. Desse modo, apresentar-se-ão os resultados oriundos das análises: Classificação Hierárquica Descendente, Análise de Similitude e Nuvem de Palavras. 


\section{Classificação Hierárquica Descendente (CHD)}

Os dados originários da entrevista e processados pelo software Iramuteq reteve um aproveitamento de $70,62 \%$ do total do corpus, o qual foi composto por 31 entrevistas, também denominado de unidades de contexto iniciais (UCIs), perfazendo 5.631 ocorrências, sendo 1.237 palavras distintas. Ao se reduzir o vocabulário às suas raízes, foram encontrados 679 radicais analisáveis e 113 unidades de contextos elementares (UCEs), que correspondem à fragmentação do texto, com o agrupamento de palavras conforme a sua forma lexical e frequência. Observa-se no dendograma (Figura 1) a CHD contendo as palavras distribuídas em cinco classes.

Figura 1. Dendograma da Classificação Hierárquica Descendente do corpus bullying e depressão elaborado por adolescentes.

\begin{tabular}{|c|c|c|c|c|c|c|c|c|c|c|c|c|c|c|c|c|c|}
\hline \multicolumn{3}{|c|}{ CLASSE 2: } & \multicolumn{3}{|c|}{ CLASSE 3: } & \multicolumn{3}{|c|}{ CLASSE 5: } & \multicolumn{3}{|c|}{ CLASSE 4: } & \multicolumn{3}{|c|}{ CLASSE 1: } & \multicolumn{3}{|c|}{ CLASSE 6: } \\
\hline \multicolumn{3}{|c|}{22 UCE - $16,2 \%$} & \multicolumn{3}{|c|}{19 UCE $-13,7 \%$} & \multicolumn{3}{|c|}{16 UCE $-15,4 \%$} & \multicolumn{3}{|c|}{16 UCE $-13,7 \%$} & \multicolumn{3}{|c|}{18 UCE $-18,8 \%$} & \multicolumn{3}{|c|}{26 UCE $22,2 \%$} \\
\hline $\begin{array}{l}\text { Palaura' } \\
\text { Atributo }\end{array}$ & $x^{2}$ & & $\begin{array}{l}\text { Palaura/ } \\
\text { Atributo }\end{array}$ & $x$ & $\mathbf{F}$ & $\begin{array}{l}\text { Palaura/ } \\
\text { Atributo }\end{array}$ & $x 2$ & $\mathbf{F}$ & $\begin{array}{l}\text { Palavra' } \\
\text { Atributo }\end{array}$ & $x^{2}$ & $\mathbf{F}$ & $\begin{array}{l}\text { Palavra' } \\
\text { Atributo }\end{array}$ & $x^{2}$ & $\mathbf{F}$ & $\begin{array}{l}\text { Palavra/ } \\
\text { Atributo }\end{array}$ & $x^{2}$ & $\mathbf{F}$ \\
\hline Triste & 53 & 141 & Cousa & 42 & 75 & Mate & 29 & 78 & Bater & 48 & 82 & Näo_é & 37 & 100 & Verbal & 25 & 82 \\
\hline Isolar & 20 & 83 & Fmamilier & 39 & 100 & Escola & 23 & 75 & Xingax. & 41 & 80 & Sempre & 19 & 70 & Físico & 24 & 150 \\
\hline Você & 20 & 50 & Sintoma & 31 & 60 & Casa & 23 & 75 & $\operatorname{Sin}$ & 40 & 87 & Como & 14 & 58 & Agredir & 21 & 150 \\
\hline Sertar & 15 & 80 & Achar & 17 & 44 & N30_serte & 23 & 100 & Mening & 26 & 83 & Tirar & 13 & 80 & \begin{tabular}{|c|} 
Conhesco \\
\end{tabular} & \begin{tabular}{|l|}
21 \\
\end{tabular} & 87 \\
\hline Doenga & 15 & 80 & Passar & 9 & 50 & Querer & 22 & 64 & Merino & 21 & 71 & Comigo & 10 & 54 & Vifions & 18 & 100 \\
\hline Auto & 15 & 80 & Emocional & 2 & 60 & Vontade & 19 & 67 & \begin{tabular}{|l|} 
Feio \\
\end{tabular} & 15 & 67 & Depois & 2 & 67 & Vivenciar & 17 & 78 \\
\hline Sentir & 11 & 50 & \begin{tabular}{|l|} 
Morte \\
\end{tabular} & 2 & 60 & Näo_querer & 17 & 80 & Raiva & 15 & 67 & Assim & 2 & 55 & Fomília & 14 & 100 \\
\hline Baixo & 11 & 55 & Ser & 2 & 25 & \begin{tabular}{|l|l} 
Sair \\
\end{tabular} & 17 & 80 & Deixorr & 14 & 55 & $\begin{array}{l}\text { Quando } \\
\end{array}$ & 8 & 35 & Bullying & 13 & 45 \\
\hline Depressäo & 2 & 33 & \begin{tabular}{|l} 
Poder \\
\end{tabular} & 2 & 31 & Nho & 15 & 62 & Algo & 13 & 75 & Brincadeira & 2 & 50 & Exemplo & 2 & 75 \\
\hline Ficar & 9 & 31 & Cortar & 2 & 66 & Dia & 13 & 67 & Amigo & 10 & 45 & Saber & $a$ & 45 & Falar & 5 & 41 \\
\hline Coisa & 2 & 32 & Afetar & 2 & 66 & Resolver & 11 & 75 & Apamhar & 2 & 67 & Näo_sei & $s$ & 50 & Quando & 4. & 35 \\
\hline Bem & 2 & 50 & Algum & 2. & 66 & Só & 9 & 43 & Medo & 2 & 50 & Mexer & 5 & 67 & Si⿱o & 4. & 43 \\
\hline Causar & 5 & 66 & Tempo & 2. & 66 & Viver & 8 & 60 & Faim & 2. & 50 & Ofender & 5 & 67 & Ano & 3. & 67 \\
\hline Estimar & $s$ & 66 & Vida & 6 & 73 & Mutar & 8 & 60 & Ficar & 5 & 24 & Incomodar & 5 & 67 & Joger & 3 & 67 \\
\hline Sua & $s$ & 66 & Também & 6 & 35 & \multirow{5}{*}{\multicolumn{3}{|c|}{$\begin{array}{c}\text { Vítimas e não } \\
\text { possuiam } \\
\text { ervolvimento } \\
\text { com o bullying }\end{array}$}} & Me Mhor & 5 & 50 & Artes & 5 & 67 & Meio & 3. & 50 \\
\hline Pessoa & 4. & 22 & Amizo & 5 & 36 & & & & Cara & 5 & 50 & $\mathrm{Mal}$ & 4. & 42 & \multirow{5}{*}{\multicolumn{3}{|c|}{$\begin{array}{l}\text { Agressores e } \\
\text { vítimas e } \\
\text { possuiam } \\
\text { envolvimento } \\
\text { com o bullying }\end{array}$}} \\
\hline Sintoma & 3 & 33 & Problema & 4 & 50 & & & & Dar & 3 & 33 & Vez & 4 & 44 & & & \\
\hline Nada & 3 & 33 & Acontecer & 4. & 33 & & & & Tomar & 3 & 40 & Falar & 3 & 32 & & & \\
\hline Praticar & 3 & 50 & Musto & 3 & 23 & & & & \begin{tabular}{|l|} 
Lewar \\
\end{tabular} & 3. & 40 & $\mathrm{Já}_{\mathrm{a}}$ & 3 & 30 & & & \\
\hline \multicolumn{3}{|c|}{$\begin{array}{c}\text { Homens, } \\
\text { Vítimas e } \\
\text { observadores do } \\
\text { bullying }\end{array}$} & \multicolumn{3}{|c|}{$\begin{array}{c}\text { Agressores e } \\
\text { vitimas do } \\
\text { bullying }\end{array}$} & & & & \multicolumn{3}{|c|}{$\begin{array}{l}\text { De } 12 \text { a } 14 \text { anos } \\
\text { e ensino } \\
\text { fundamental }\end{array}$} & \multicolumn{3}{|c|}{ Consensual } & & & \\
\hline
\end{tabular}

Nota: F: Frequência, $X^{2}$ : Qui- quadrado. Fonte: Autoria Própria.

No dendrograma denominado "Representações Sociais acerca do bullying e depressão no contexto escolar", observase uma primeira partição composta por seis classes distintas, agrupadas em dois subcorpora. O primeiro, localizado à esquerda, aglutinou as classes 2 e 3, resultando em um campo conceituado "Atitudes e Implicações do bullying e depressão", e do lado direito do dendrograma, o agrupamento das classes 5, 4, 1 e 6 denominado "Tipos de bullying no contexto escolar", que por sua vez se subdividiu originando de um lado a junção das classes 5, 4 e 1, intitulada "Contexto estrutural e implicações veladas do bullying" e o último campo, o qual também foi subdividido gerando à esquerda a classe 5 intitulada "Contexto estrutural do bullying" e do outro, a junção das classes 4 e 1, denominada "Implicações veladas do bullying". Por outro lado, nesse mesmo bloco, nota-se mais afastada a classe 6, conceituada "Tipos de bullying". 
Percebe-se que o agrupamento dos subcorpora à esquerda (classes 2 e 3) foi resultante de um bloco textual semelhante, assim como o da subcorpora à direita formado pela junção das classes 4 e 1, o que permite inferir que suas classes possuem significados complementares, distinguindo-se do discurso da classe 6, uma vez que está mais afastada. Foram consideradas as formas com frequência igual ou superior à média de ocorrência (22) e com $\chi^{2}$ superior a 3,84.

A classe 2, "Comportamentos do bullying e da depressão", composta por 16,2\% dos segmentos de texto representada, sobretudo, pelos enunciados dos adolescentes do sexo masculino, vítimas e observadores do bullying. Com palavras/radicais no intervalo de $\chi^{2}=3$ (praticar) a $\chi^{2}=53$ (triste), esta classe apresentou o bullying e a depressão enquanto condutas de isolamento, que podem ser sintomas interligados aos dois fenômenos, como aponta os fragmentos de frases a seguir:

Os sintomas são se isolar, você fica sem fazer nada, não se comunica, e fica com a autoestima baixa, o bullying pode causar a depressão. E algumas pessoas se sentem um nada depois que aquilo aconteceu e elas se isolam a elas mesmos e ali começam a ficar a ter depressão. A doenças que as vezes é causada pelo bullying, que a pessoa está tão afetada que começa a se sentir culpada pelas coisas que acontecem e tipo, ela fica muito triste e guarda isso pra ela e meio que fica se isolando.

De acordo com o conhecimento dos adolescentes nessa classe 1 os sintomas de bullying e depressão foram representados similarmente ao conhecimento científico. Conforme o (DSM-5), os principais sintomas de depressão são: humor depressivo, diminuição no interesse para a maioria das atividades, alteração no sono, no apetite, agitação ou diminuição psicomotora, sensação de fadiga, sentimentos de inutilidade, indecisão e ideação suicida. E para o bullying, observa-se que pode existir relações entre ser vítima de bullying e apresentar sintomas de depressão e ansiedade (Monteiro et al., 2020).

Neste estudo, destaca-se a conduta de isolamento, similarmente ao estudo de Bissoto e Silva (2017), ao averiguarem o bullying em relação aos alunos com necessidades educacionais especiais. Nesse contexto, notou-se a atitude de se isolar como resultante de uma fragilidade na trama das relações sociais estabelecidas nas escolas. Observou-se que os comportamentos de isolamento podem se referir tanto às consequências adotadas frente às atitudes de intimidação proferidas pelos colegas no contexto escolar, como podem estar classificadas conforme as ações praticadas como é o caso da esfera social no qual existe a tendência em ignorar, isolar e excluir a vítima (Monteiro et al., 2020).

Nesse mesmo direcionamento, observa-se a classe 3 "Implicações psicoemocionais do bullying" a qual reteve 13,7\% dos segmentos de texto, e por sua vez abrangeu palavras/radicais no intervalo de $\chi^{2}=3$ (muito) a $\chi^{2}=42$ (causa) e foi representada por agressores e vítimas do bullying. Nessa classe, é possível perceber por meio dos relatos que tristeza, desânimo, baixo rendimento escolar, problemas familiares e a falta de apoio são algumas das consequências do bullying.

Os sintomas são desânimo, se excluir dos amigos, baixo rendimento escolar e acho que também afeta a saúde. Outras causas podem ser problemas familiares. Os sintomas são tristezas frequentemente, a pessoa fica muito fraca e frágil e sempre vive com o emocional abalado, a mais calada da turma. As causas podem ser a falta de amigos no dia a dia e a falta de apoio familiar, também acho que é isso. Aí todas as coisas e as brincadeiras que as pessoas faziam comigo me atacavam e eu ficava bem triste, eu não achei nenhum método ainda, e de certa forma o único momento que eu estou em paz é quando eu durmo.

Nesta ótica, tanto as vítimas quanto os agressores sofrem as consequências das atitudes vinculadas ao bullying, especialmente no que se refere aos efeitos negativos à saúde mental, física e social dos envolvidos. Conforme Naveed et al., (2019), a depressão, ansiedade, solidão, baixo rendimento escolar, comportamentos inadequados no contexto social, alto risco para abuso de substâncias, danos pessoais e suicídio são algumas das implicações que os comportamentos da violência bullying podem ocasionar. 
A literatura também preconiza uma correlação positiva entre o score de depressão e bullying, inferindo que quanto maior o sofrimento do bullying maior o nível de depressão (Monteiro et al., 2020). Além disso, são verdadeiras as relações entre ser vítima de bullying e apresentar sintomas de depressão e ansiedade, além de pobre saúde geral e ideação suicida, podendo, inclusive, o jovem ser mais propenso a usar substâncias ilícitas (Fernandes, 2021).

A classe 5, por sua vez, aborda o "contexto estrutural do bullying", representada por 15,4\%, foi composta majoritariamente pelo discurso das vítimas e das pessoas que não possuíam envolvimento com o bullying. Esta classe abrangeu palavras/radicais no intervalo de $\chi^{2}=8$ (matar) a $\chi^{2}=29$ (mãe), apresentando, na descrição dos participantes, a escola como ponto inicial desse tipo de violência que perpassa o contexto escolar, invade a vida familiar e revela, na figura da mãe, um ponto forte, fatores estes que podem ser devidamente observados através dos relatos a seguir:

Eles mexeram comigo, chamaram nome com a minha mãe e eu não gostei, acabei indo para cima deles. Não tinha pra que aquilo, minha mãe estava no trabalho, não estava lá para se defender. De uns tempos pra cá eu já vi minha irmã passando por isso e minha mãe foi conversar com as pessoas, ela foi resolver isso na escola e depois de um trabalho sobre bullying na escola acabou que as pessoas começaram a se dar melhor. Já vivenciei o bullying na escola onde eu estudava. Olhe, a minha atitude na verdade foi a de chamar a diretora para ela resolver tipo com a pessoa que eu não conhecia, aí eu não podia me intrometer.

Nesses relatos, observa-se também que a figura da mãe emerge tanto vinculada ao aspecto positivo quanto negativo. No positivo, quando a mesma intervém procurando ajuda para o filho no âmbito escolar, demonstrando preocupação com o seu bemestar, estando presente em seu convívio cotidiano e no lado oposto, a mãe que mesmo sabendo que comportamentos inadequados vinculados ao bullying ocorrem, não demonstra interesse em verificar os fatos ocorridos, deixando o adolescente à margem do cuidado materno. O apoio é de suma importância nessa fase do desenvolvimento humano.

A classe 4, traz à tona o "conceito do bullying e depressão" e contendo 13,7\% das pseudofrases, nela, observa-se a predominância do discurso dos adolescentes pertencentes a faixa etária dos 12 aos 14 anos, do ensino fundamental. Esta classe abrangeu palavras/radicais no intervalo de $\chi^{2}=3$ (levar;) a $\chi^{2}=48$ (bater). Dentro desse panorama, visualiza-se que os participantes descrevem o bullying como algo ruim que envolve não apenas o ato de bater, como também, xingar, apelidar, provocar humilhações, rejeição e violência com o intuito de sentir poder, e querer fazer mal ao outro. Assim como relatam as experiências vividas, sejam essas como vítimas ou observadores diante de tais agressões. Já a depressão é descrita pelos estudantes como uma doença em que as pessoas negligenciam a higiene pessoal, como é o caso de não tomar banho, o que pode ser observado através dos relatos a seguir:

É coisa muito feia que pode fazer com que algo muito ruim aconteça. Sim, eu vi uma amiga minha apanhando e eu não fiz nada senão eu ia apanhar também. É como você se dá o direito de xingar ou diminuir outra pessoa ou para se sentir melhor e mais poderoso ou só por ela ser diferente de você e você querer humilhar ela e você bater na pessoa ou fazer danos psicológicos. Coisa muito ruim que dá raiva, envolve xingar e bater. Sim, os meninos me chamam de macumbeira e dizem que meu lanche tem feitiço. É um negócio que a pessoa mexe com a outra porque não gosta dela, bate na pessoa, xinga e fica com raiva. Eu fico sendo chamado de baleia e eu não gosto disso. Os meninos não deixam eu brincar de bola porque dizem que eu sou gordo. Depressão é a pessoa que está doente. Depressão é a pessoa que fica sem tomar banho.

Percebe-se que o conhecimento dos escolares sobre o bullying e depressão se apresenta similar ao conceito delimitado pela literatura científica, descrevendo o bullying de modo análogo ao universo reificado, por meio do qual esse fenômeno é entendido como a expressão de uma relação desigual de poder, pautada em atitudes agressivas e intencionais (apelidar, excluir, bater, espancar) de uma pessoa ou um grupo contra outra(s), que desempenham distintos papéis sociais ou tipos de envolvimento nesse contexto (Olweus, 2013; Bandeira \& Hutz, 2012). Semelhantemente ao constatado no estudo de Cavalcanti et al. (2019) 
gerando, inclusive, impactos de múltiplas ordens aos envolvidos, como é o caso da depressão. Conforme o CID-10 (1993), a depressão apresenta os principais sintomas: redução da possibilidade de sentir prazer, diminuição da concentração, fadiga após mínimo esforço, alterações no sono, aumento/diminuição de apetite, redução da autoestima e autoconfiança e culpabilidade. Observa-se também nas narrativas, que o bullying é ocasionado por atitudes de exclusão quando um grupo menospreza o outro com base em suas diferenças físicas ou comportamentais, repercutindo na intolerância entre os grupos.

No que tange à classe 1, intitulada "Brincadeiras ofensivas", obteve o percentual de 18,8\% dos segmentos textuais, tendo sido representada pelo discurso consensual dos adolescentes. Esta classe abrangeu palavras/radicais no intervalo de $\chi^{2}=3$ (já) a $\chi^{2}=37$ (não é), visualiza-se, que para os participantes a utilização de termos e atitudes relativas à inferiorização das características físicas e sociais são caracterizadas como brincadeiras, conforme observa-se nas pseudofrases a seguir;

Ficavam: a negrinha não sei o que, volta para senzala, essas coisas. Primeiro eu chorava, desde pequena sempre mexeram muito comigo, aí de primeira eu chorava muito e então a pessoa cresce e vai ficando com raiva. Antes não passava de brincadeira, eu não sei como me sentir. Sempre quando vem tirar onda eu tiro onda também, um xinga o outro, fala mal da aparência, e é assim que acontece. Eles sempre faziam algo que me incomodava, falavam várias coisas, zoavam coisas minhas como aparelho, e eu não fiz nada. Já vivenciei. Quando eu era menor, era muito tímida e quieta, e eu sempre fui a menina que quase não falava muito na sala. Por isso as pessoas tiravam muitas conclusões sem me conhecer, e tinham outras alunas que eram um pouco maiores e que ficavam mexendo comigo.

Conforme os relatos apresentados, nota-se o bullying naturalizado enquanto sinônimo de brincadeira, no entanto são atitudes ofensivas relacionadas principalmente às características físicas das vítimas. Percebe-se que esse entendimento de brincadeira é uma forma de amenizar o sentimento de culpa dos agressores e de menor valia para as vítimas. Para Fonseca et al. (2017), por ser habitualmente associado a "brincadeiras" típicas do cotidiano estudantil, o bullying ainda é visto como natural e, logo, aceitável, realidade que pode inviabilizar o seu efetivo enfrentamento na instituição, dado esse identificado em estudos anteriores.

Chama atenção ainda para a menção do racismo associado ao bullying relatada nas pseudofrases. Nesse aspecto, verificase uma sobreposição de dois processos sociais, uma vez que o aluno se torna vítima tanto do racismo quanto do bullying, desse modo, além dos danos advindos da violência entre pares no contexto escolar, vemos emergir implicações de ordem macrossocial, relacionados às diferenças étnico-raciais, o que corrobora com pesquisas anteriores (Myers \& Bhopal, 2017; Palmer et al., 2017).

Tais achados levantam uma questão tradicional dos estudos em torno do bullying: a sua relação com o preconceito. Para Antunes e Zuin (2008), bullying e preconceito referem-se a um mesmo fenômeno, sendo o último a base do primeiro. Não obstante, Crochík (2015), por sua vez, defende a distinção desses fenômenos ao dizer que no preconceito, há um alvo fixo, enquanto no bullying, qualquer um pode sofrer a agressão. Independente dos dissensos teóricos, os estudos convergem para o fato de que há uma sobreposição do bullying com fenômenos sociais que envolvem preconceito (Cavalcanti et al, 2019), como por exemplo a LGBTfobia (Neves et al.., 2019), preconceito de gênero (Ramos-Jiménez et al., 2017).

A classe 6, intitulada "Tipos de bullying", representando $22,2 \%$ do total das UCEs, foi composta a partir do discurso dos agressores e vítimas que possuíam envolvimento com o bullying. Esta classe abrangeu palavras/radicais no intervalo de $\chi^{2}=3$ (meio) a $\chi^{2}=25$ (verbal). Nesse direcionamento, visualiza-se que os participantes detectam o bullying a partir de suas vivências com o bullying verbal, físico e psicológico, manifesto por meio de agressões físicas e falas que diminuem e inferiorizam os colegas, conforme as UCEs a seguir;

Vai desde a agressão verbal até a exclusão que não depende nem de agressão ou de atos diretos com palavras ou contato físico, basta excluir alguém de um grupo... Físico é a pessoa partindo para lhe agredir e o verbal que é com palavras. Os tipos são agressão física e verbal. E meio que agressão verbal é na verdade esse o tipo de bullying que conheço. O que fala é o verbal e o que te agride... Conheço vários tipos de bullying: xingar, bater, colocar apelido e rejeitar. 
A literatura especializada classifica os tipos de bullying conforme as ações praticadas, a saber: verbal - visualizados comportamentos de insultar, xingar e apelidar pejorativamente; moral, onde percebe-se a difamação, calúnia; o sexual, no qual envolve o assédio; no social, as pessoas podem ignorar, isolar e excluir; o bullying psicológico envolve a perseguição, amedrontamento, entre outros. Na violência física, observa-se agressões físicas, o material: furtar, roubar, destruir pertences de outrem; e o virtual, praticado por meios eletrônicos no qual envolve a depreciação do outro, enviar mensagens intrusivas da intimidade, enviar ou adulterar fotos e dados pessoais que resultem em sofrimento ou com o intuito de criar meios de constrangimento psicológico e social (Bissoto \& Silva, 2017). Neste estudo os adolescentes demonstraram o conhecimento sobre os tipos de bullying mais voltados para os aspectos verbais (xingar, apelidar), físicos (bater) e psicológico (rejeitar).

\section{Análise de Similitude}

Para complementar a análise hierárquica descendente, realizou-se a análise de similitude (Figura 2) e nuvem de palavras (Figura 3). Na similitude, é possível identificar tanto as palavras de maior recorrência, assim como as que têm conexidade entre si. Ressalta-se que 639 palavras fizeram parte dessa análise com ocorrência mínima de 4.

Figura 2. Resultados da Análise de Similitude (AS) acerca do bullying e depressão.

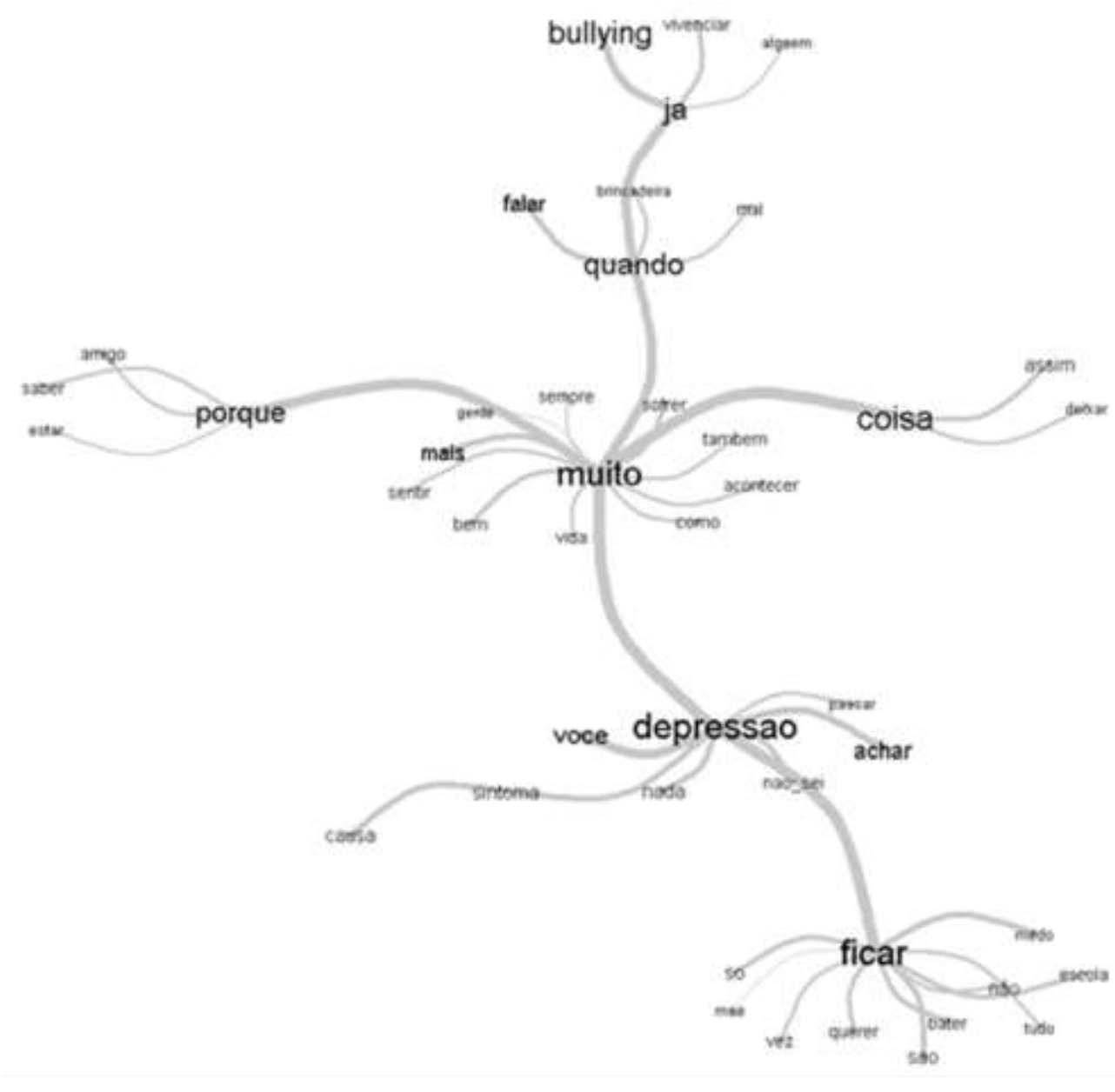

Fonte: Autoria Própria.

Dessa forma, observa-se que as objetivações mais nucleares foram: "muito, depressão, ficar, coisa, bullying, quando, porque e já", desse modo, essa análise ancorou-se na identificação da estrutura do campo representacional dos fatores associados 
ao bullying e a depressão. O advérbio "muito" conota a intensidade com a qual os construtos analisados acontecem, assim como dimensiona a grande proporção e a constância do sofrimento, este, capaz de ocasionar a depressão.

As demais objetivações, conforme visualiza-se na figura 2, estiveram mais na periferia da análise, as quais representam o bullying enquanto um tipo de brincadeira que ocorre com frequência quando, no falar e nos tipos de brincadeiras de forma repetitiva, surgem comportamentos depreciativos que sempre causam sofrimento e medo, realizada ou observada por colegas no ambiente escolar, elementos esses também visualizados na análise hierárquica descendente.

\section{Nuvem de Palavras}

Complementando os resultados da análise de similitude, a nuvem de palavras (Figura 3) trouxe estruturas do conteúdo acerca do bullying e da depressão, que esteve ligada a elementos voltados para a prática do bullying e suas consequências, tais como exemplificados pelas objetivações “cortar", "só”, “agressão". No nível mais superficial, observa-se o destaque das palavras depressão, muito, bullying e em segundo plano as palavras medo, causa, sintoma, sofrer, o que correlacionam com o sofrimento psíquico expressado por meio das falas.

Figura 3. Nuvem de Palavras acerca do bullying e depressão.

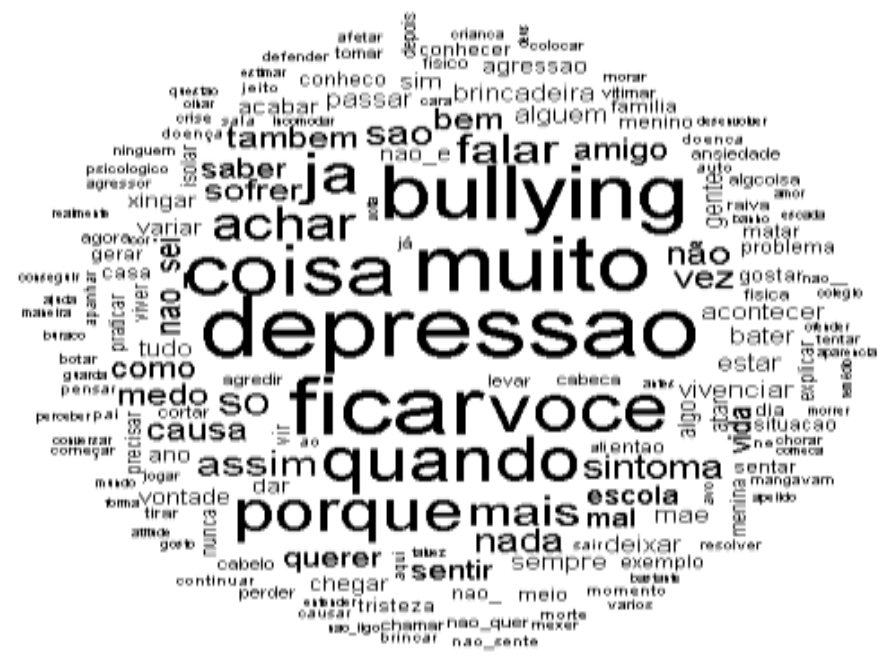

Fonte: Autoria Própria.

Tais achados evidenciados na análise de similitude e nuvem de palavras se coadunam com os resultados obtidos nas pesquisas de Forlim et al. (2014), Valle et al. (2015), Cosma et al. (2015), Ato et al. (2018) e Azúa et al. (2020) quando fazem referência à relação direta entre o bullying e a ocorrência de emoções negativas, sintomas de depressão e ideação suicida, conforme os autores essa prevalência seria maior no caso das vítimas do bullying.

\section{Considerações Finais}

Face ao objetivo de apreender as representações sociais elaboradas por adolescentes acerca do bullying e da depressão, foi possível identificar que os conhecimentos sobre esses fenômenos se encontram entrelaçados, principalmente no que tange às condutas de isolamento. Os atores sociais demonstraram ter entendimento acerca do bullying e da depressão, ressaltando seu significado multifacetado, ancorando-os nas vertentes conceitual, comportamental, implicações psicoemocionais, tipos bullying e bullying enquanto sinônimo de brincadeira. 
Outro aspecto de notoriedade no estudo foi a aproximação do contexto escolar com o familiar revelado na figura da mãe protetora que intervêm e fornece apoio, e a negligente, que mesmo tendo conhecimento das vivências cotidianas sobre o bullying, não interferem. No que tange aos tipos de bullying, os de maior evidência foram a agressão física, verbal e psicológica, o que pode levar a transtornos mentais, como é o caso da depressão, descrita pelos participantes do estudo como uma doença em que as pessoas negligenciam a higiene pessoal, tristeza, desânimo, baixo rendimento escolar, problemas familiares e a falta de apoio.

Os adolescentes também descreveram o bullying como algo ruim que envolve não apenas o ato de bater, como também, xingar, apelidar, provocar humilhações, rejeição e violência com o intuito de sentir poder e querer fazer mal ao outro. Não obstante, esses mesmos participantes delineiam esse fenômeno com naturalidade enquanto sinônimo de brincadeira. Como pode ser considerado uma brincadeira, se os próprios atores sociais reconhecem que o bullying é algo danoso à saúde mental, pois inferiorizam e excluem o outro?

Esses achados de considerarem o bullying enquanto brincadeira pode ser uma forma de minimizarem o sentimento de culpa dos agressores e de menor valia das vítimas. Diante dessas evidências, chama-se a atenção para não se considerar o bullying como uma brincadeira. Assim, espera-se que esses resultados se configurem como respaldo para novas pesquisas e ações práticas nas escolas e no contexto familiar com a finalidade de reduzir as atitudes do bullying. Dessa forma, para compreender os fenômenos bullying e depressão foi necessário entender como as representações sociais foram construídas por esse grupo de pertença observando seus significados e vivências cotidianas.

Nota-se algumas limitações no presente estudo, a exemplo da utilização de uma amostra não probabilística, a aplicação de apenas um instrumento para apreender as RS e os participantes estarem vinculados a uma única instituição da rede pública de ensino. Dessa forma, sugere-se cautela ao comparar estes resultados aos de outros autores. Para estudos futuros, recomenda-se a ampliação da amostra incluindo instituições da rede privada de ensino e a aplicação de outros instrumentos, como é o caso da associação livre de palavras.

\section{Agradecimentos}

Agradecemos ao Centro Universitário - UNIESP pelo fomento da pesquisa.

\section{Referências}

Antunes, D. C., \& Zuin, A. Á. S. (2008). Do bullying ao preconceito: os desafios da barbárie à educação. Psicologia \& Sociedade, 20, 33-41. 10.1590/S010271822008000100004

Aragão, T. A., Coutinho, M. P. L., Araújo, L. F. D., \& Castanha, A. R. (2009). Uma perspectiva psicossocial da sintomatologia depressiva na adolescência. Ciência \& Saúde Coletiva, 14, 395-405. https://www.scielo.br/j/csc/a/TXfgjHZQHBTJ9TWQ73vVPBK/?format=pdf\&lang=pt

Araújo, L. S.; Coutinho, M. P. L.; Miranda, R. S.; Saraiva, E. R. A. (2012). Universo consensual de adolescentes acerca da violência escolar. Psico-USF, 17(2), 243-251. https://doi.org/10.1590/S1413-82712012000200008

Associação Psiquiátrica Americana. (2013). Manual Diagnóstico e Estatístico de Transtornos Mentais (5 a ed.). Arlington, VA. American Psychiatric Publishing Ato, R. S., Estrada, M. A. V., Mejia, C. R., \& Alvarado, J. C. (2018). Riesgo suicida asociado a bullying y depresión en escolares de secundaria. Revista chilena de pediatría, 89(2), 208-215. https://dx.doi.org/10.4067/s0370-41062018000100209

Azúa F. E, Carvallo, P. R. \& Poblete, S. R. (2020). Acoso escolar (bullying) como fator de riesgo de depresión y suicidio. Revista chilena de pediatría, 91 (3), 432-439. https://dx.doi.org/10.32641/rchped.v91i3.1230

Bandeira, C., \& Hutz, C. S. (2012). Bullying: prevalência, implicações e diferenças entre os gêneros. Psicologia Escolar e Educacional, 16(1), 35-44. https://abrapee.files.wordpress.com/2012/02/abrapee_v16n1-1.pdf

Bissoto, M. L., \& Silva, D. F. (2017). O fenômeno do bullying em relação aos alunos com necessidades educacionais especiais: um estudo a partir do cotidiano escolar. Revista Cocar, 11(22), 327-346.

Camargo, B. V., \& Justo, A. M. (2013). IRAMUTEQ: Um software gratuito para análise de dados textuais. Temas em Psicologia, 21(2), 513-518. https://doi.org/10.9788/TP2013.2-16 
Cavalcanti, J. G., Coutinho, M. P. L., Araújo, L. S., Pinto, A. V. L., Do Bu, E. A., \& Silva, K. C. (2019). Bullying no contexto da adolescência: um estudo das representações sociais. Revista de Psicologia da IMED, 11(2), 96-114. https://dx.doi.org/10.18256/2175-5027.2019.v11i2.3287

CID-10. Classificação de Transtornos Mentais e de Comportamento da CID-10: Descrições clínicas e diretrizes diagnósticas. 1993: Artmed.

Cosma, A., Balazsi, R. \& Baban, A. (2015). Bullying in romanian school children: the role of substance abuse. Psicologia, Saúde \& Doenças, 16(1), 44-56. https://doi.org/10.15309/15psd160206

Crochick, J. L. (2019). Preconceito e bullying: marcas da regressão psíquica socialmente induzida1 2. Psicologia USP, 30. 10.1590/0103-6564e190006

Fante, C. (2005). Fenômeno bullying: Como prevenir a violência nas escolas e educar para a paz. Campinas: Versus.

Fernandes, G. (2021). Delineamento, implementação e avaliação de intervenção antibullying no contexto escolar. Tese (doutorado em Educação) - Universidade La Salle, Canoas, Disponível em: http://hdl.handle.net/11690/1765. Acesso em: 05 jul. 2021.

Fonseca, K. B. C., Micucci, M. D., Costa, P. D. S., Lemes, S., Santos, N. D. A., \& Cunha, J. V. A. D. (2017). The incidence of Bullying in Business Administration and Accounting Courses. Psicologia Escolar e Educacional, 21(1), 79-92. https://doi.org/10.1590/2175- 3539201702111079

Forlim, B.G. et al. (2014). Relação entre bullying e sintomas depressivos em estudantes do ensino fundamental. Estudos de Psicologia, Campinas 31(3) pp. 367375 .

Garcia, S. A. B. (2013). Escola multicultural: a sala de aula como espaço de integração e inclusão social (Doctoral dissertation, Faculdade de Ciências Sociais e Humanas, Universidade Nova de Lisboa). http://hdl.handle.net/10362/12144

Heloani, R., \& Pinto, E. (2017). Aspectos teóricos y conceptuales del bullying y del acoso moral/Teoretical and conceptual aspects of Bullying and Moral Harassment. Praxis, (21), 93-110. http://200.14.87.198/index.php/praxis/article/view/62

Lopes, A. A., Neto. (2005). Bullying - comportamento agressivo entre estudantes. Jornal de Pediatria, 81(5), 164-172. https://www.scielo.br/j/jped/a/gvDCjhggsGZCjttLZBZYtVq/?format=pdf\&lang=pt

Myers, M., \& Bhopal, K. (2017). Racism and bullying in rural primary schools: protecting White identities post Macpherson. British journal of sociology of education, 38(2), 125-143.

Monteiro, F. R., Coutinho, M. P. L., \& Araújo, L. F. (2007). Sintomatologia depressiva em adolescentes do ensino médio: um estudo das representações sociais. Psicologia: Ciência e Profissão, 27(2), 224-235 https://doi.org/10.1590/S1414-98932007000200005

Monteiro, R. P., Medeiros, E. D., Pimentel, C. E., Gouveia, R. S. V., \& Gouveia, V. V. (2020). Valores sociais atenuam sintomas depressivos em vítimas de bullying. Psico, 51(1), e29342. https://doi.org/10.15448/1980-8623.2020.1.29342

Montejo, A. M. M, González, E. Z. \& Albarrán, J. M. L. (2019). ¿Qué saben nuestros niños de la escuela primaria sobre acoso escolar? Pediatría Atención Primaria, 21(82), 121-129. http://scielo.isciii.es/scielo.php?script=sci_arttext\&pid=S1139-76322019000200002\&lng=es\&tlng=es

Moscovici, S. (2012). Representações sociais: investigações em psicologia social. Petrópolis: Vozes, 2009.

Naveed, Sadiq et al. (2019). Association of bullying experiences with depressive symptoms and psychosocial functioning among school going children and adolescents. BMC research notes, 12(1). https://doi.org/10.1186/s13104-019-4236-X

Neves, S., Borges, J., Silva, E., Vieira, C. P., \& Sousa, A. N. (2019). Bullying homofóbico: Crenças e práticas de estudantes do Ensino Superior em Portugal. Psicologia, 33(2), 47-59. 10.17575/rpsicol.v33i2.1460

Palmer, S. B., Cameron, L., Rutland, A., \& Blake, B. (2017). Majority and minority ethnic status adolescents' bystander responses to racism in school. Journal of Community \& Applied Social Psychology, 27(5), 374-380. 10.1002/casp.2313.

Oliveira-Menegotto, L. M., Pasini, A. I., \& Levandowski, G. (2013). O bullying escolar no Brasil: uma revisão de artigos científicos. Psicologia: teoria e prática, 15(2), 203-215. http://pepsic.bvsalud.org/scielo.php?script=sci_arttext\&pid=S1516-36872013000200016\&lng=pt\&tlng=pt.

Olweus, D. (2013). School bullying: Development and some important challenges. Annual Review of Clinical Psychology, 9(1), 751-780. https://doi.org/10.1146/annurevclinpsy-050212-185516

OMS. Organização Mundial de Saúde. (2021). https://www.paho.org/pt/topicos/depressao.

Palomares-Ruiz, A. Oteiza-Nascimento, A., Toldos, M. P., Serrano-Marugán, I., M. \& Babarro, J. M. (2019). Bullying and depression: the moderating effect of social support, rejection and victimization profile. Anales de Psicología, 35(1), 1-10. https://dx.doi.org/10.6018/analesps.35.1.301241

Ramos-jiménez, Arnulfo et al. Prevalence of bullying by gender and education in a city with high violence and migration in Mexico. Revista panamericana de salud publica, 41, e37, 2017.

Resett, S. (2018). Estabilidade de ser vitimizado, ser agressor, problemas emocionais e comportamentais em adolescentes: Estabilidade ou mudança? Interdisciplinar, 35 (2), 341-362. http://www.scielo.org.ar/scielo.php?script=sci_arttext\&pid=S1668-70272018000200006\&lng=es\&tlng=es.

Ribeiro, K. C. S., Coutinho, M. P. L., \& Nascimento, E. S. (2010). Representação social da depressão em uma Instituição de Ensino da Rede Pública. Psicologia: Ciência e Profissão, 30(3), 448-463. https://doi.org/10.1590/S1414-98932010000300002

Sá, C. P. (1998). A construção do objeto de pesquisa em representações sociais. UERJ.

Schoombie, E. \& van Zyl, E. (2011). Die voorkoms van depressiesimptome onder 12- en 13-jarige leerders. Tydskrif vir Geesteswetenskappe, 51(1), 53-67. http://www.scielo.org.za/scielo.php?script=sci_arttext\&pid=S0041-47512011000100004\&lng=en\&tlng=af. 
Research, Society and Development, v. 10, n. 16, e369101623617, 2021

(CC BY 4.0) | ISSN 2525-3409 | DOI: http://dx.doi.org/10.33448/rsd-v10i16.23617

Terroso, L. B., Wendt, G. W., Oliveira, M. D. S., \& Argimon, I. I. D. L. (2016). Habilidades sociais e bullying em adolescentes. Temas em Psicologia, 24(1), 251-259. https://doi. org/10.9788/TP2016.1-17

Valle, J. E., Stelko-Pereira, A. C., Sá, L. G. C. \& Williams, L. C. A. (2015). Violência, depressão e engajamento. Revista Quadrimestral da Associação Brasileira de Psicologia Escolar e Educacional, 19(3). 463-473.

Vieira, F. H. M., Alexandre, H. P., Campos, V. A., \& Leite, M. T. de S. (2020). Impactos do bullying na saúde mental do adolescente. Ciência ET Praxis, 13(25), 91-104. https://revista.uemg.br/index.php/praxys/article/view/4354 